\title{
The Relationship between Stock Returns and Volatility in the Seventeen Largest International Stock Markets: A Semi-Parametric Approach
}

\author{
Dimitrios Dimitriou, Theodore Simos \\ Department of Economics, University of Ioannina, Ioannina, Greece \\ E-mail:tsimos@cc.uoi.gr \\ Received November 4, 2010; revised December 5, 2010; accepted January 1, 2011
}

\begin{abstract}
We empirically investigate the relationship between expected stock returns and volatility in the twelve EMU countries as well as five major out of EMU international stock markets. The sample period starts from December 1992 until December 2007 i.e. up to the recent financial crisis. Empirical results in the literature are mixed with regard to the sign and significance of the mean - variance tradeoff. Based on parametric GARCH in mean models we find a weak relationship between expected returns and volatility for most of the markets. However, using a flexible semi-parametric specification for the conditional variance, we unravel significant evidence of a negative relationship in almost all markets. Furthermore, we investigate a related issue, the asymmetric reaction of volatility to positive and negative shocks in stock returns confirming a negative asymmetry in almost all markets.
\end{abstract}

Keywords: Risk-Return Tradeoff, International Stock Markets, Semi-Parametric Specification of Conditional Variance

\section{Introduction}

An important topic in asset valuation research is the tradeoff between volatility and return (typically log price changes). The theoretical asset pricing models [1-5] link returns of an asset to its own variance or to the covariance between the returns of stock and market portfolio. However, whether such a relationship is positive or negative has been controversial. As summarized in [6], most asset-pricing models [1-4] suggest a positive tradeoff for expected returns and volatility. On the other hand, there are many empirical studies that confirm a negative relationship between returns and volatility: [7-10]. Reference [11] indicates that there is a strong positive relationship between risk and excess return while $[12,13]$ as well as [9] found negative relationship in a variety of USA market indices. Reference by [14] using data from the $S \& P$ index, find a negative relationship between unexpected volatility and excess returns. Similar are the findings of [15] which use a two regime model. According to [14] argue that the observed negative relationship provides indirect evidence of a positive relationship between expected risk premium and exante volatility. In other words, if expected risk premiums are positively related to predictable volatility, then a positive unexpected change in volatility increases future expected risk premiums and lowers current stock prices. [16] also points to a positive relationship between risk and return for USA monthly and daily returns over the period 1926-1988. [17,18] in various assets of USA market find a negative relationship before 1990. [19] reports no significant relationship in USA stock market at the same period. Also, [20] suggests that the relationship between risk and return may be time varying. These conflicting empirical results in the literature warrant further examination using different and probably more appropriate econometric techniques.

In this work we utilize a flexible functional form to model conditional variance. We favour this approach, given that estimation via a parametric GARCH-M model is prone to model misspecifications. Consistent estimation of a GARCH-M model requires that the full model is correctly specified [21]. Indeed, the problem that inferences drawn on the basis of GARCH-M models may be susceptible to model misspecification is well known to applied researchers. [18] argues that parameter restric- 
tions imposed by GARCH models may unduly restrict the dynamics of the conditional variance process. In contrast, a semi-parametric specification of the conditional variance allows flexible functional forms, and therefore can lead potentially to more reliable estimation and inference. In this paper, we propose three parametric GARCH-M models and a semi-parametric model for testing the null hypothesis of zero GARCH in mean effect. We then apply the above models to daily empirical data of seventeen largest international stock markets and two world indices. We show some evidence that a significant negative relationship between stock market returns and market volatility prevails in most major stock markets.

Moreover the paper investigates the asymmetric impact of positive and negative shocks on volatility using two parametric models: EGARCH-M and AGARCH-M. [21-23] provide thorough surveys in this area.

The rest of this paper is organized as follows. Section two discusses the parametric and semi-parametric models used in the present empirical analysis, section three presents the data, in section four we test the forecasting power of each model, in section five we interpret the empirical results and in section six we conclude the paper.

\section{The Parametric GARCH-M Model with $t$ Distributed Innovations}

The model is specified as follows:

$$
\begin{aligned}
& y_{t}=\mu+\sum_{s=1}^{k} b_{s} y_{t-s}+\delta \sigma_{t}^{2}+u_{t} \\
& u_{t}=\varepsilon_{t} \sigma_{t} \\
& \varepsilon_{t} \mid \Omega_{t-1} \sim t . d .\left(0, \sigma_{t}, v\right), \\
& \sigma_{t}^{2}=\omega+\sum_{i=1}^{q} a_{i} \varepsilon_{t-1}^{2}+\sum_{i=1}^{p} \beta_{i} \sigma_{t-1} .
\end{aligned}
$$

The dependent variable $y_{t}$ denotes the stock market returns, $\sigma_{t}^{2}$ their conditional variance and $u_{t}$ the disturbance term. We assume that the random term $\varepsilon_{t}$ is distributed as the student's $t$ with $v$ degrees of freedom. Equation (1) represents dynamic changes in the mean returns, while Equation (4) describes time variation in the conditional variance. The information available at period $t-1$ is denoted by $\Omega_{t-1}$. The conditional variance $\sigma_{t}^{2}$ in (4), is modelled according to ARCH - GARCH (q, p) specification of [24]. Among all the parameters to be estimated, the most relevant for this study is the parameter $\delta$. The sign and significance of the parameter defines the relationship between stock market returns and conditional variance. Setting $a_{i}+\beta_{i}=1$ implies a highly persistent conditional variance. This model is known as the integrated GARCH or IGARCH which is more likely for daily data series.

\subsection{Parametric EGARCH-M Model}

In this case the model is specified as follows:

$$
\begin{aligned}
& y_{t}=\mu+\sum_{s=1}^{k} b_{s} y_{t-s}+\delta \sigma_{t}^{2}+u_{t} \\
& u_{t}=\varepsilon_{t} \sigma_{t}, \\
& \varepsilon_{t} \mid \Omega_{t-1} \sim \text { n.d. }(0,1), \\
& \log \sigma_{t}^{2}=a_{0}+\sum_{i=1}^{p} a_{i}\left\{\theta_{1} \varepsilon_{t-i}+\theta_{2}\left(\left|\varepsilon_{t-i}\right|-E\left|\varepsilon_{t}\right|\right)\right\} \\
& \quad+\sum_{i=1}^{p} \beta_{i} \log \sigma_{t-i}^{2} .
\end{aligned}
$$

The EGARCH specification allows the conditional variance process to respond asymmetrically to positive and negative shocks. This is reflected in the value of the parameter product $\alpha_{i} \theta_{1}$. When $\alpha_{i} \vartheta_{1}<0(>0)$, the variance tends to rise (fall) when the shock is negative (positive).

\subsection{The Asymmetric GARCH-M (GJR) Model}

In order to capture the asymmetric impact of new information on volatility [25] suggested the GJR-GARCH (q, p) model. It is specified by the following equations:

$$
\begin{aligned}
& y_{t}=\mu+\sum_{s=1}^{k} b_{s} y_{t-s}+\delta \sigma_{t}^{2}+u_{t} \\
& u_{t}=\varepsilon_{t} \sigma_{t}, \\
& \varepsilon_{t} \mid \Omega_{t-1} \sim t . d .\left(0, \sigma_{t}, v\right), \\
& \sigma_{t}^{2}=\omega+\sum_{i=1}^{q} a_{i} \varepsilon_{t-1}^{2}+\kappa_{2} D_{t-1} \varepsilon_{t-1}^{2}+\sum_{i=1}^{p} \beta_{i} \sigma_{t-1} .
\end{aligned}
$$

The conditional variance equation (12) includes an extra term: the dummy variable $D_{t-1}$, it is equal to one when $\varepsilon_{t-1}$ is negative (good news), and equal to zero when $\varepsilon_{t-1}$ is positive (bad news). A statistically significant parameter $\kappa_{2}$ indicates volatility clustering. In case $\kappa_{2}>0$ there are leverage effects while when $\kappa_{2}=0$ the news impact curve is symmetric, i.e. past positive shocks have the same impact as past negative shocks on today's volatility.

\subsection{A Semi-Parametric GARCH-M Specification}

We consider the following semi-parametric GARCH-M 
model

$$
y_{t}=a_{0}+a_{1} y_{t-1}+\delta \sigma_{t}^{2}+u_{t} \equiv x_{t} a+u_{t},
$$

where $y_{t}$ is the stock market returns, $x_{t}=\left(1, y_{t-1}, \sigma_{t}^{2}\right)$, $a=\left(a_{0}, a_{1}, \delta\right)^{\prime}$ is a vector of parameters to be estimated, $\sigma_{t}^{2}=\operatorname{var}\left(y_{t}, \Omega_{t-1}\right)$ is the conditional on $\Omega_{t-1}$ variance of $y_{t}, \Omega_{t-1}$ is the information set available up to time $t-1$. The error term is a martingale difference process, i.e., $E\left(u_{t} \mid \Omega_{t-1}\right)=0$. We are interested in testing the null hypothesis of $H_{0}: \delta=0$ versus $H_{1}: \delta \neq 0$. The null hypothesis implies that the conditional variance $\sigma_{t}^{2}$ does not affect the returns $y_{t}$. We first examine a simple semi-parametric GARCH model of the form

$$
\sigma_{t}^{2}=m\left(u_{t-1}\right)+\gamma \sigma_{t-1}^{2},
$$

where the functional form of $m(\cdot)$ is not necessary specified parametrically. In case $m\left(u_{t-1}\right)=a+\beta u_{t-1}^{2}$ the model is reduced to the standard $\operatorname{GARCH}(1,1)$ specification. Under the null $H_{0}: \delta=0$ using (13), we obtain $u_{t-1}=y_{t-1}-a_{0}-a_{1} y_{t-2}$. Then, we can generalize (14) as follows

$$
\operatorname{var}\left(\left.y_{t}\right|_{t-1}\right)=\sigma_{t}^{2}=g\left(y_{t-1}, y_{t-2}\right)+\gamma \sigma_{t-1}^{2},
$$

where

$$
g\left(y_{t-1}, y_{t-2}\right)=m\left(y_{t-1}-a_{0}-a_{1} y_{t-2}\right)=m\left(u_{t-1}\right)
$$

Expression (15) allows the conditional variance to depend on lagged values of $y_{t}$. Denoting $z_{t-1}=\left(y_{t-1}, y_{t-2}\right)$ and substituting (15) recursively yields

$$
\begin{aligned}
\sigma_{t}^{2}= & g\left(z_{t-1}\right)+\gamma g\left(z_{t-2}\right)+\gamma^{2} g\left(z_{t-3}\right) \\
& +\cdots+\gamma^{d-1} g\left(z_{t-d}\right)+\cdots
\end{aligned}
$$

Given that $0<\gamma<1$, we may approximate (16) by a finite lag model of length $d$ :

$$
\begin{aligned}
\sigma_{t}^{2}= & g\left(z_{t-1}\right)+\gamma g\left(z_{t-2}\right)+\gamma^{2} g\left(z_{t-3}\right) \\
& +\cdots+\gamma^{d-1} g\left(z_{t-d}\right)
\end{aligned}
$$

Equation (17) is a restricted additive model with the restriction that the different additive functions $g(\cdot)$ are proportional to each other. The model allows lagged $y_{t-s}$ being included at the right-hand side of (17). [26], in a similar framework, suggests a kernel-based method to estimate the model. Although Equation (17) is only a two-dimensional non-parametric model, it can be difficult to estimate by the popular kernel method, especially when $d$ is large. Moreover, when $d$ is large, the kernel method can give quite unreliable estimates due to its failure to impose the additive model structure. In this work we opt to estimate (17) by the non-parametric series method. The advantage of using a series method is that the additive proportional model structure is imposed directly and the estimation is performed in one step. To this end, let $\left\{\phi_{i}(y)\right\}_{i}^{\infty}=0$ denote a series-based function that can be used to approximate any univariate function $m(y)$. We can use a linear combination of the product base function to approximate $g\left(y_{t-1}, y_{t-2}\right)$,

$$
\text { i.e. } \begin{aligned}
\sum_{i=0}^{q} & \sum_{i^{\prime}=0}^{q} a_{i i^{\prime}} \phi_{i}\left(y_{t-s}\right) \phi_{i^{\prime}}\left(y_{t-s-1}\right) \\
= & a_{00} \phi_{0}\left(y_{t-s}\right) \phi_{0}\left(y_{t-s-1}\right)+\cdots+a_{0 q} \phi_{0}\left(y_{t-s}\right) \phi_{q}\left(y_{t-s-1}\right) \\
& +a_{10} \phi_{1}\left(y_{t-s}\right) \phi_{0}\left(y_{t-s-1}\right)+\cdots+a_{0 q} \phi_{1}\left(y_{t-s}\right) \phi_{q}\left(y_{t-s-1}\right) \\
& +\cdots+a_{q 0} \phi_{q}\left(y_{t-s}\right) \phi_{0}\left(y_{t-s-1}\right)+\cdots \\
& +a_{q q} \phi_{q}\left(y_{t-s}\right) \phi_{q}\left(y_{t-s-1}\right), \quad s=1, \cdots, d .
\end{aligned}
$$

After re-arranging terms, the approximating function is of the form:

$$
\begin{aligned}
\sigma_{t}^{2} \cong & a_{00} \sum_{s=1}^{d} \gamma^{s-1} \phi_{0}\left(y_{t-s}\right) \phi_{0}\left(y_{t-s-1}\right)+\cdots \\
& +a_{0 q} \sum_{s=1}^{d} \gamma^{s-1} \phi_{0}\left(y_{t-s}\right) \phi_{q}\left(y_{t-s-1}\right) \\
& +a_{10} \sum_{s=1}^{d} \gamma^{s-1} \phi_{1}\left(y_{t-s}\right) \phi_{0}\left(y_{t-s-1}\right)+\cdots \\
& +a_{1 q} \sum_{s=1}^{d} \gamma^{s-1} \phi_{1}\left(y_{t-s}\right) \phi_{q}\left(y_{t-s-1}\right) \\
& +a_{q 0} \sum_{s=1}^{d} \gamma^{s-1} \phi_{q}\left(y_{t-s}\right) \phi_{0}\left(y_{t-s-1}\right)+\cdots \\
& +a_{q q} \sum_{s=1}^{d} \gamma^{s-1} \phi_{q}\left(y_{t-s}\right) \phi_{q}\left(y_{t-s-1}\right) .
\end{aligned}
$$

There are $(q+1)^{2}+1$ parameters, namely $\gamma$ and $a_{i j}(i, j=0, \cdots, q)$. Note that the number of parameters in model (18) does not depend on the number of lags included in the model. For example, if $q$ is fixed, then the number of parameters is also fixed. Therefore, we can let $d \rightarrow \infty$ as $T \rightarrow \infty$ (with $d / T \rightarrow 0$ ). Asymptotically, it allows an infinite lag structure without the curse of dimensionality problem (since $q$ is independent of $d$ ). The estimation procedure is as follows: Under $H_{0}: \delta=0$ we obtain $y_{t}=a_{0}+a_{1} y_{t-1}+u_{t}$. Define $\widetilde{y}_{t}=y_{t}-a_{0}$ $-a_{1} y_{t-1}$, then $E\left(\widetilde{y_{t}^{2}} \mid \Omega_{t-1}\right)=\sigma_{t}^{2}$ and

$$
\widetilde{y_{t}}=\sigma_{t}^{2}+v_{t},
$$

where $E\left(\widetilde{y_{t}^{2}} \mid \Omega_{t-1}\right)=0$. Using the series approximation of $\sigma_{t}^{2}$ in (18) we substitute out $\sigma_{t}^{2}$ in (19), and replacing $a_{0}$ and $a_{1}$ by the least squares estimators of $a_{0}$ and $a_{1}$, we can estimate the parameters $\gamma$ and $a_{i j}$ 's using nonlinear least squares methods. Alternatively, one can estimate $a_{i j}, i, j=0,1, \cdots, q$, by least squares, regressing $y_{t}^{2}\left(\widetilde{y_{t}^{2}}\right)$ on the series approximating base functions, and searching over the grid $\gamma \in[0,1]$ for optimizing values. In order to ensure that the above pro- 
cedure leads to a consistent estimate of the $g(\cdot)$ function, we need to let $q \rightarrow \infty$ and $q / T \rightarrow 0$ as $T \rightarrow \infty$. The condition $q \rightarrow \infty$ ensures that the asymptotic bias goes to zero. For example, if one uses power series as the base function, then it is well known that the approximation error of using a q-th order polynomial goes to zero as $q \rightarrow \infty$. The condition $q / T \rightarrow 0$ ensures that the estimation variance goes to zero as sample increases. See $[27,28]$ for more details on the rate of convergence of series estimation.

Let ${\widehat{\sigma_{t}}}^{2}$ denote the resulting nonparametric series estimator of $\sigma_{t}^{2}$. Replacing $\sigma_{t}^{2}$ by ${\widehat{\sigma_{t}}}^{2}$ in Equation (13), we get

$$
y_{t}=a_{0}+a_{1} y_{t-1}+\delta{\widehat{\sigma_{t}^{2}}}^{2}+\varepsilon_{t},
$$

where $\varepsilon_{t}=u_{t}+\delta\left(\sigma_{t}^{2}-\hat{\sigma}_{t}^{2}\right)$. We then estimate the parameters vector $a=\left(a_{0}, a_{1}, \delta\right)^{\prime}$ by least squares. Equation (20) contains a non-parametrically generated regressor $\hat{\sigma}_{t}^{2}$. Let $\hat{a}=\left(\hat{a}_{0}, \hat{a}_{1}, \hat{\delta}\right)$ ' denote the resulting estimator. If one estimate the conditional variance ignoring the additive structure of $\sigma_{t}^{2}$, then can use the results of [30] and obtain the asymptotic distribution of $\hat{a}$ from:

$$
\sqrt{n}(\hat{a}-a) \rightarrow N(0, \Sigma)
$$

where $\Sigma$ is the asymptotic covariance matrix. Based on the least squares estimation of (18), the non-parametric estimator $\hat{\sigma}_{t}^{2}$, is consistent under the null hypothesis of $H_{0}: \delta=0$.

Next, we discuss the selection of the number of lags $d$ and the order of series approximation $q$, in finite sample applications. For a fixed value of $q$, the number of parameters to be estimated is fixed and does not depend on $d$. In particular, choosing a large value of $d$ does not lead to over fitting because the number of parameters that need to be estimated does not vary as $d$ increases. Therefore, it makes sense to select the value of $q$ that minimizes the AKAIKE information criteria.

\section{Description of the Data}

To estimate the models we use daily US-dollar denominated returns ${ }^{1}$ on stock indices of seventeen countries: the twelve stock markets of the European Monetary Union, Italy (ITA), Greece (GRE), Germany (GER), France (FRA), Finland (FIN), Belgium (BEL), Austria (AUS), Ireland (IRL), Netherlands (NETH), Luxemburg (LUX), Spain (SPN), Portugal (POR), as well as the United States of America (USA), the United Kingdom (UK),

${ }^{1}$ As suggested by [31], calculating the returns in U.S. dollars eliminates the local inflation.
Japan (JAP), Sweden (SWD) and Russia (RUS). We also include two world stock-indices: the international index of DataStream's stock-exchange markets (D-W.I.) (this includes stocks from the most developed markets worldwide and it remains through many years one of the most recognized indices in the world) and the M.S.C.I (Morgan Stanley Capital International) world index, which is a stock index of the international market. The last index includes stocks from 23 developed markets. It is computed since 1969 and has been a common evaluation index of the international stock-markets.

The data set starts from $4^{\text {th }}$ December of 1992 and end up at $5^{\text {th }}$ December of 2007, comprising 3.914 observations. The source is the DataStream database. Daily returns of each country are calculated using the first logarithmic differences of general indices that include dividends.

\section{Forecasting Power of the Models}

In this section we empirically investigate the four models, stated in Section 2, in terms of their forecasting ability. The test statistic is the mean absolute error (MAE) which is a measurement of the co-cumulative forecasting error of the model. In our analysis the MAE is calculated from the monthly sub-samples of observations. Therefore, we are able to obtain a MAE figure for each month. The results are presented on Table 1 . We notice that the best forecasting model is the semi-parametric. In almost all markets the average MAE of the semi-parametric model is smaller of that of the parametric models. The second best forecasting model is EGARCH except of Japan and Italy where the GARCH-M and AGARCH- $\mathrm{M}$ models provide a smaller MAE. Moreover, the models GARCH-M and AGARCH-M have a similar forecasting ability with AGARCH-M being slightly ahead. Based on the results reported in Table 1 we conclude that forecasting ability of the semi-parametric model is broadly superior.

\section{Empirical Results}

Notice that the conditional variance of the returns for each market is calculated using the stock returns instead of the excess stock returns. The excess return of a stock is defined as the difference between return and the risk-free rate that is dominant in the market. [6,18,29,30] agree that using returns is broadly equivalent with excess returns. In the present study for the estimation of the conditional variance we use returns computed by $\log$ price differences. For the three models: GARCH-M, EGARCH-M, and AGARCH-M, we decide the appropriate distribution and number of lags $p$ and $q$ based on the AKAIKE criterion. So, for the models GARCH-M 
Table 1. Results of the mean of the mean absolute forecasting errors of the four models.

\begin{tabular}{|c|c|c|c|c|c|c|c|c|c|}
\hline MARKET & AUS & BEL & FIN & GER & GRE & IRL & ITA & JAP & LUX \\
\hline garch-m & 0.01035 & 0.009 & 0.01266 & 0.01 & 0.01237 & 0.01121 & 0.0072 & 0.01240 & 0.005394 \\
\hline egarch-m & 0.008160 & 0.008 & 0.03916 & 0.0077 & 0.01101 & 0.01045 & 0.0096 & 0.13893 & 0.00393 \\
\hline agarch-m & 0.010169 & 0.009 & 0.00877 & 0.0095 & 0.01242 & 0.01118 & 0.0068 & 0.01225 & 0.005452 \\
\hline semi-par & $2.52 \mathrm{E}-07$ & $8.9 \mathrm{E}-6$ & 0.01264 & 0.007 & 0.00843 & 0.01047 & 0.0067 & 0.00926 & 0.00317 \\
\hline FRA & NETH & POR & RUS & SPN & SWD & UK & USA & D-W.I. & M.S.C.I. \\
\hline 0.00994 & 0.009523 & 0.0085 & 0.0165 & 0.0100 & 0.01372 & 0.0086 & 0.007 & 0.00702 & 0.0067297 \\
\hline 0.00926 & 0.008817 & 0.0075 & 0.0115 & 0.0080 & 0.01228 & 0.00808 & 0.0073 & 0.00622 & 0.006395 \\
\hline 0.00979 & 0.009236 & 0.0084 & 0.0142 & 0.0099 & 0.01341 & 0.0082 & 0.0075 & 0.00687 & 0.006534 \\
\hline 0.0074891 & 0.007609 & 0.0060 & 0.0110 & 0.0074 & 0.00991 & 0.0075 & 0.0055 & 0.00508 & 0.005276 \\
\hline
\end{tabular}

Table 2. Parameter estimates for all four models.

\begin{tabular}{|c|c|c|c|c|c|c|c|c|c|}
\hline MARKET & AUS & BEL & FIN & GER & GRE & IRL & ITA & JAP & LUX \\
\hline \multicolumn{10}{|l|}{ garch-m } \\
\hline$\delta$ & $0.0094 * * *$ & 0.01 & $-0.041 * * *$ & 0.00492 & 0.06 & $-0.008 * * *$ & -0.0341 & $0.055 * * *$ & 0.039 \\
\hline (t-stat) & $(14.5)$ & $(0.003)$ & $(-25.6)$ & $(0.0021)$ & $(0.036)$ & $(-23.2)$ & $(-0.016)$ & $(39.6)$ & $(0.016)$ \\
\hline $\boldsymbol{\alpha}_{\mathrm{i}}+\boldsymbol{\beta}_{\mathrm{i}}$ & 0.8764 & 0.9921 & 0.9921 & 0.964 & 0.9928 & 0.9341 & 0.9808 & 0.9612 & 0.9944 \\
\hline \multicolumn{10}{|l|}{ egarch-m } \\
\hline$\delta$ & -0.204 & 0.297 & -0.0128 & -0.0065 & 0.15 & 0.26 & -2.061 & 2.788 & -0.585 \\
\hline (t-stat) & $(-0.03)$ & $(0.087)$ & $(-0.011)$ & $(-0.002)$ & $(0.088)$ & $(0.121)$ & $(-1.27)$ & $(0.91)$ & $(-0.162)$ \\
\hline \multicolumn{10}{|l|}{ agarch-m } \\
\hline$\delta$ & $0.0083 * * *$ & 0.03 & -0.0144 & $0.01 * * *$ & 0.072 & 0.00057 & 0.0403 & $0.18 * * *$ & 0.029 \\
\hline (t-stat) & (11.0) & $(0.01)$ & $(-0.013)$ & $(30.2)$ & $(0.042)$ & $(0.531)$ & $(0.0186)$ & $(-175.00)$ & $(0.0119)$ \\
\hline $\boldsymbol{\alpha}_{\mathrm{i}}+\boldsymbol{\beta}_{\mathrm{i}}$ & 0.8401 & 0.9849 & 0.989 & 0.939 & 0.986 & 0.9003 & 0.959 & 0.954 & 0.9941 \\
\hline$\kappa_{2}$ & $0.0037 * * *$ & $0.062 * * *$ & $0.0029 * * *$ & $0.0031 * * *$ & $0.0032 * * *$ & $0.0037 * * *$ & $0.003^{* * *}$ & $0.0049 * * *$ & 0.00048 \\
\hline (t-stat) & $(2.18)$ & $(3.15)$ & $(1.56)$ & $(4.26)$ & (3.63) & $(4.47)$ & $(4.39)$ & (4.67) & $(0.621)$ \\
\hline \multicolumn{10}{|l|}{ semi-par } \\
\hline$\delta$ & $0.0002 * * *$ & $0.06 * * *$ & $-6.57 * * *$ & $-16 * * *$ & $-9.6 * * *$ & $-13.27 * * *$ & $-13 * * *$ & $-3.62 * *$ & $6.66 * * *$ \\
\hline (t-stat) & $(8.26)$ & $(16.0)$ & $(-7.97)$ & $(-10.8)$ & $(-9.5)$ & $(-6.7)$ & $(-9.247)$ & $(-2.32)$ & $(2.91)$ \\
\hline FRA & NETH & POR & RUS & SPN & SWD & $\mathbf{U K}$ & USA & D-W.I. & M.S.C.I. \\
\hline 0.0115 & 0.018 & 0.031 & 0.019 & 0.008 & 0.0003 & 0.0085 & 0.05 & 0.008 & 0.03 \\
\hline$(0.0042)$ & $(0.0077)$ & $(0.01)$ & $(0.0067)$ & $(0.0026)$ & $(0.00016)$ & $(0.0025)$ & $(0.022)$ & $(0.0023)$ & $(0.0092)$ \\
\hline 0.9603 & 0.9906 & 0.9964 & 0.9536 & 0.939 & 0.993 & 0.9466 & 0.998 & 0.955 & 0.9944 \\
\hline 1.059 & 0.79 & 0.248 & -0.367 & 0.059 & 0.778 & -0.33 & 0.533 & 3.919 & -0.146 \\
\hline$(0.361)$ & $(0.298)$ & $(0.046)$ & $(-0.366)$ & $(0.0019)$ & $(0.44)$ & $(-0.054)$ & $(0.18)$ & (1.13) & $(0.0361)$ \\
\hline 1.054 & 0.067 & 0.029 & 0.05 & $0.01 * * *$ & 0.0791 & 0.06 & 4.58 & 0.054 & 0.081 \\
\hline$(0.018)$ & $(0.024)$ & $(0.0097)$ & $(0.0172)$ & $(-196.00)$ & $(0.035)$ & $(0.018)$ & $(0.018)$ & $(0.014$ & $(0.021)$ \\
\hline 0.936 & 0.987 & 0.9954 & 0.9485 & 0.9272 & 0.9876 & 0.9274 & 0.9826 & 0.9257 & 0.9839 \\
\hline$-0.0041 * * *$ & $0.0043 * * *$ & $0.001 * * *$ & 0.00244 & $0.003 * * *$ & $0.0063 * * *$ & $0.0043 * * *$ & $0.004 * * *$ & $0.0032 * * *$ & $0.0035^{* * *}$ \\
\hline (5.11) & $(-5.26)$ & (1.53) & $(1.30)$ & $(2.90)$ & (4.69) & (14.6) & $(8.62)$ & $(8.24)$ & (8.39) \\
\hline$-9.83 * * *$ & $-12.86 * * *$ & $-15.0 * * *$ & $-8.16^{* * *}$ & $-22.0 * * *$ & $-8.96 * * *$ & $-15.87 * * *$ & $-16.0 * * *$ & $-25.4 * * *$ & $-15.94 * * *$ \\
\hline$(-6.36)$ & $(-11.49)$ & $(-8.5)$ & $(-8.07)$ & $(-9.85)$ & $(-9.04)$ & $(-9.75)$ & $(-12.21)$ & $(-10.77)$ & $(-7.85)$ \\
\hline
\end{tabular}

$*$ denotes statistical significance at $10 \%$ level, $* *$ denotes statistical significance at $5 \%$ level, $* * *$ denotes statistical significance at $1 \%$ level. 
and AGARCH-M the best results are derived using the t-student distribution, while for EGARCH-M the normal distribution has prevailed. ${ }^{2}$

\subsection{Interpretation of the Empirical Results}

The parameter, $\delta$, is estimated using the models of Section 2. In Table 2 we notice that with the GARCH-M specification, parameter $\delta$ is statistically significant at $1 \%$ level in Austria, Finland, Ireland and Japan. Also we notice a negative relationship in Finland and Ireland and a positive relationship in the other two mark ets. On the other hand, with EGARCH-M models $\delta$ is not statistically significant at all levels. Next we estimate the asymmetric GARCH-M model. According to the results of Table 2 it is obvious that only for Austria, Germany and Japan $\delta$ is statistical significant at $1 \%$ level. Also we observe a positive relationship between the returns and conditional variance for these three markets. Finally, we estimate the semi-parametric model using B-splines approximating base functions [32]. In all markets under examination $\delta$ is statistically significant at $1 \%$ level (with the exception of Japan where the estimate of the parameter $\delta$ is statistically significant at $5 \%$ ). The negative relationship between return and conditional variance is dominant in almost all markets except Austria, Belgium and Luxemburg. Notice that the empirical results of the parametric models are in broad agreement with those of the semi-parametric model. However, the best forecasting ability and parameter estimate's statistical significance of the semi-parametric model renders it more reliable.

Estimates of asymmetry parameters are stated in Table 3. We notice that asymmetric response of the conditional variance is a dominant property of the countries under examination. Moreover, from Table 2, parameter estimates of $\kappa_{2}$ for all the markets, except France, exhibit positive signs at $1 \%$ level, confirming the existence of a negative asymmetry. Given the fact that the semiparametric specification fits better the data this study tends to support the claim that volatility is negatively correlated with returns. Notice that the above results are consistent with the empirical findings of $[10,31,33]$, but contradict empirical findings of an insignificant relationship reported in $[29,30,34]$.

Table 3. Parameter estimates of the EGARCH-M model.

\begin{tabular}{|c|c|c|c|c|c|c|c|c|c|}
\hline MARKET & AUS & BEL & FIN & GER & GRE & IRL & ITA & JAP & LUX \\
\hline$\alpha_{\mathrm{i}} \theta_{1}, \alpha_{\mathrm{i}}=1$ & $-0.065^{* * *}$ & $-0.06^{* * *}$ & $-0.068^{* *}$ & $-0.05^{* * *}$ & -0.0217 & -0.0217 & $-0.03 * * *$ & $-0.046^{* * *}$ & -0.00716 \\
\hline (t-stat) & $(-2.87)$ & $(-4.87)$ & $(-2.31)$ & $(-4.18)$ & $(-1.28)$ & $(-1.28)$ & $(-2.79)$ & $(-2.93)$ & $(0.618)$ \\
\hline$\alpha_{2} \theta_{1}$ & $-0.0350 * *$ & & $-0.04 * * *$ & $-0.09 * * *$ & -0.0594 & & & $-0.067 * * *$ & $0.0097 * * *$ \\
\hline (t-stat) & $(-2.10)$ & & $(-3.15)$ & $(68.6)$ & (1.63) & & & $(4.02)$ & (7.61) \\
\hline$\alpha_{3} \theta_{1}$ & $-0.05646^{*}$ & & $-0.0498 *$ & $-0.05 * * *$ & -0.0014 & & & -0.0092 & -0.008559 \\
\hline (t-stat) & $(-1,92)$ & & $(-8.79)$ & $(-121)$ & $(0.105)$ & & & $(0.748)$ & (4.04) \\
\hline$\alpha_{4} \theta_{1}$ & & & $-0.0199 *$ & & 0.0313 & & & 0.0187 & \\
\hline (t-stat) & & & $(-1.54)$ & & $(-1.44)$ & & & $(-1.45)$ & \\
\hline FRA & NETH & POR & RUS & SPN & SWD & UK & USA & D-W.I. & M.S.C.I. \\
\hline$-0.0525 * * *$ & $-0.058 * * *$ & $-0.05^{* *}$ & -0.0337 & -0.0508 & $-0.08 * * *$ & $-0.08 * * *$ & $-0.1 * * *$ & $-0.11 * * *$ & $-0.06 * * *$ \\
\hline \multirow[t]{7}{*}{$(-3.44)$} & $(-5.31)$ & $(-2.08)$ & $(-0.62)$ & $(-0.501)$ & (3.65) & $(-3.48)$ & $(-5.83)$ & $(-5.24)$ & $(-2.04)$ \\
\hline & & $-0.03 * * *$ & $-0.061 * *$ & -0.0576 & 0.00968 & $-0.09 * * *$ & & $-0.09 * * *$ & \\
\hline & & $(1.20)$ & (2.13) & $(0.589)$ & $(-0.497)$ & (72.5) & & $(-3.95)$ & \\
\hline & & -0.0786 & $-0.053^{* *}$ & -0.0392 & 0.00365 & & & -0.0146 & \\
\hline & & $(0.621)$ & (1.94) & $(0.309)$ & $(-0.179)$ & & & $(-0.643)$ & \\
\hline & & -0.0458 & -0.027 & & 0.0191 & & & & \\
\hline & & $(-1.49)$ & $(1.17)$ & & $(-1.28)$ & & & & \\
\hline
\end{tabular}

$*$ denotes statistical significance at $10 \%$ level, $* *$ denotes statistical significance at $5 \%$ level, $* * *$ denotes statistical significance at $1 \%$ level.

${ }^{2}$ Full table of results are available upon request. 


\section{Conclusions}

In this paper we empirically investigated the relationship between expected returns and conditional variance in twelve stock markets of the European Union as well as five large stock markets and two world indices. Most asset pricing models [1-4] predict a positive risk- return tradeoff. In order to investigate this, both parametric and semi-parametric estimation methods of the conditional variance have been applied to daily data from the above markets. Based on the semi-parametric specification, we find a statistically significant negative relationship of the risk-return tradeoff in most markets. There are only three exceptions: Austria, Belgium and Luxemburg. Furthermore, we find significant evidence of a negative asymmetry in almost all markets confirming the previous empirical findings.

\section{Acknowledgements}

We wish to thank an anonymous referee of this Journal for his/her useful comments, which improved the paper. The usual disclaimer applies.

\section{References}

[1] W. F. Sharpe, "Capital Asset Prices: A Theory of Market Equilibrium under Conditions of Market Risk," Journal of Finance, Vol. 19, No. 3, September 1964, pp. 425-442. doi: $10.2307 / 2977928$

[2] J. Linter, "The Valuation of Risky Assets and the Selection of Risky Investments in Stock Portfolios and Capital Budgets," Review of Economics and Statistics, Vol. 47, No. 1, February 1965, pp. 13-37. doi:10.2307/1924119

[3] J. Mossin, "Equilibrium in a Capital Asset Market," Econometrica, Vol. 34, No. 4, October 1966, pp. 768-783. doi: $10.2307 / 1910098$

[4] R. C. Merton, "An Intertemporal Capital Asset Pricing Model," Econometrica, Vol. 41, No. 5, September 1973, pp. 867-887. doi:10.2307/1913811

[5] R. C. Merton, "On Estimating the Expected Return on the Market: An Exploratory Investigation," Journal of Financial Economics, Vol. 8, No. 4, 1980, pp. 323-361. doi:10.1016/0304-405X(80)90007-0

[6] R. T. Baillie and R. P. DeGennaro, "Stock Returns and Volatility," Journal of Financial and Quantitative Ana1ysis, Vol. 5, No. 2, June 1990, pp. 203-214.

[7] F. B1ack, "Studies of Stock Price Volatility Changes," Proceedings of the 1976 Meeting of Business and Economics Statistics Section of the American Statistical Association, Vol. 27, 1976, pp. 399-418.

[8] J. Cox and S. Ross, "The Valuation of Options for Alternative Stochastic Process," Journal of Financial Economics, Vol. 3, No.1-2, 1976, pp. 145-166.
[9] G. Bakaert and G. Wu, "Asymmetric Volatility and Risk In Equity Markets," Review of Financial Studies, Vol. 13, No. 1, 2000, pp. 1-42. doi:10.1093/rfs/13.1.1

[10] R. Whitelaw, "Stock Market Risk and Return: An Empirical Equilibrium Approach," Review of Financial Studies, Vol. 13, No. 3, 2000, pp. 521-547. doi: $10.1093 / \mathrm{rfs} / 13.3 .521$

[11] R. Pindyck, "Risk, Inflation and the Stock Market," American Economic Review, Vol. 74, 1984, pp. 335-351.

[12] R.J. Shiller, "Do Prices Move too Much to be Justified by Subsequent Changes in Dividends," American Economic Review, Vol. 71, No. 3, June 1981, pp. 421-436.

[13] J. Poterba and L. Summers, "The Persistence of Volatility and Stock Market Fluctuations," American Economic Review, Vol. 76, No. 5, 1986, pp. 1142-1151.

[14] K. R. French, G. W. Schwert and R. F. Stambaugh, "Expected Stock Returns and Volatility," Journal of Financial Economics, Vol. 19, No. 1, 1987, pp. 3-30. doi:10.1016/0304-405X(87)90026-2

[15] H. A. Shawky and A. Marathe, "Expected Stock Returns and Volatility in a Two Regime Market," The Journal of Economics and Business, Vol. 47, No. 5, December 1995, pp. 409-422. doi:10.1016/0148-6195(95)00035-6

[16] J. Y. Campbell and L. Hentschel, "No News is Good News: An Asymmetric Model of Changing Volatility in Stock Returns," Journal of Financial Economics, Vol. 31, No. 3, 1992, pp. 281-318. doi:10.1016/0304-405X(92)90037-X

[17] E. F. Fama and W. G. Schwert, "Asset Returns and Inflation," Journal of Financial Economics, Vol. 5, No. 2, 19 77, pp. 115-146.

[18] D. Nelson, "Conditional Heteroscedasticity in Asset Returns: A New Approach," Econometrica, Vol. 59, No. 2, March 1991, pp. 347-370. doi:10.2307/2938260

[19] K. C. Chan, A. Karolyi and R. Stulz, "Global Financial Markets and the Risk Premium on US Equity," Journal of Financial Economics, Vol. 32, No. 2, 1992, pp. 137-167. doi:10.1016/0304-405X(92)90016-Q

[20] C. R. Harvey, "Time-Varying Conditional Covariances in Tests of Asset Pricing Models," Journal of Financial Economics, Vol. 24, No. 2, 1989, pp. 289-317. doi:10.1016/0304-405X(89)90049-4

[21] T. Bollers1ev, R. Y. Chou and K. F. Kroner, "ARCH Modeling in Finance: A Review of the Theory and Empirical Evidence," Journal of Econometrics, Vol. 52, No. 1-2, 1992, pp. 5-59.

[22] T. Bollerslev, R. F. Engle and D. B. Nelson, "ARCH Models," In: R. F. Engle and D. McFadden, Eds., Handbook of Econometrics, North-Holland, Vol. 4, 1994, pp. 2959-3038.

[23] H. Ludger, "All in the Family Nesting Symmetric and Asymmetric GARCH Models," Journal of Financial Economics, Vol. 39, No. 1, September 1995, pp. 71-104. doi:10.1016/0304-405X(94)00821-H

[24] T. Bollerslev, "Generalized Autoregressive Conditional Heteroscedasticity," Journal of Econometrics, Vol. 31, 
No. 3, 1986, pp. 307-327.

[25] R. F. Engle and V. K. Ng, "Measuring and Testing the Impact of News on Volatility," Journal of Finance, Vol. 48, No. 5, 1993, pp. 1749-1778.

[26] L. Yang, "Direct Estimation in an Additive Model When the Components are Proportional," Statistica Sinica, Vol. 12, No. 3, 2002, pp. $801-821$.

[27] W. Newey, "Convergence Rates and Asymptotic Normality for Series Estimators," Journal of Econometrics, Vol. 79, No. 1, July 1997, pp. 147-168. doi:10.1016/S0304-4076(97)00011-0

[28] R. De Jong, "Convergence Rates and Asymptotic Normality for Series Estimators: Uniform Convergence Rates," Joumal of Econometrics, Vol. 111, No 1, 2002, pp. 1-9.

[29] T. Choudhry, "Stock Market Volatility and the Crash of 1987: Evidence from Six Emerging Markets," Journal of Intemational Money and Finance, Vol. 15, No. 6, 1996, pp. 969-981.
[30] C. F. Lee, G. Chen and O. Rui, "Stock Returns and Volatility on China's Stock Markets," Journal of Financial Research, Vol. 24, No. 4, 2001, pp. 523-543.

[31] L. R. Glosten, R. Jagannathan and D. E. Runkle, "On the Relation between the Expected Value and Volatility of Nominal Excess Return on Stocks," Journal of Finance, Vol. 48, No. 5, 1993, pp. 1629-1658. doi: $10.2307 / 2329067$

[32] L. L. Schumaker, "Spline Functions: Basic Theory," Wiley, New York, 1981.

[33] Q. Li, J. Yang, C. Hsiao and Y. -J. Chang, "The Relationship between Stock Returns and Volatility in International Stock Markets," Journal of Empirical Finance, Vol. 12, No. 5, December 2005, pp. 650-665. doi:10.1016/j.jempfin.2005.03.001

[34] P. Theodossiou and D. Lee, "Relationship between Volatility and Expected Returns Across International Stock Markets," Journal of Business Finance and Accounting, Vol. 22, No. 2, March 1995, pp. 289-300. doi:10.1111/j.1468-5957.1995.tb00685.x 